\title{
Исследование кинетики гибели неравновесных носителей заряда в четверных соединениях меди $\mathrm{Cu}_{2-\delta} \mathrm{NiSnS}_{4}(0 \leq \delta \leq 0.2)$
}

\author{
(ㄱ М.В. Гапанович ${ }^{1}$, Е.В. Рабенок ${ }^{1}$, Б.И. Голованов ${ }^{1}$, Д.М. Седловец ${ }^{3}$, Г.Ф. Новиков ${ }^{1,2}$ \\ ${ }^{1}$ Институт проблем химической физики Российской академии наук, \\ 142432 Московская обл., Черноголовка, Россия \\ ${ }^{2}$ Московский государственный университет им. М.В. Ломоносова \\ (факультет фундаментальной физико-химической инженерии), \\ 119991 Москва, Россия \\ ${ }^{3}$ Институт проблем технологии микроэлектроники и особо чистых материалов Российской академии наук, \\ 142432 Московская обл., Черноголовка, Россия \\ E-mail: gmw@icp.ac.ru
}

Поступила в Редакцию 12 мая 2021 г.

В окончательной редакции 25 июля 2021 г.

Принята к публикации 18 августа 2021 г.

\begin{abstract}
Методом твердофазного синтеза из элементных $\mathrm{Cu}, \mathrm{Ni}, \mathrm{Sn}$ и $\mathrm{S}$ получены образцы $\mathrm{Cu}_{2-\delta} \mathrm{NiSnS}_{4}$ $(0 \leq \delta \leq 0.2)$. Уточнены параметры их кристаллической решетки. Впервые бесконтактным методом времяразрешенной микроволновой фотопроводимости оценены времена жизни фотогенерированных носителей заряда в $\mathrm{Cu}_{2-\delta} \mathrm{NiSnS}_{4}$. Времена оказались $\tau \approx 7 \mathrm{Hc}$, что сопоставимо с литературными данными для кестеритов CZTS. При этом в кинетике гибели фотогенерированных носителей заряда наблюдается преобладание процессов бимолекулярной рекомбинации над процессами захвата.
\end{abstract}

Ключевые слова: $\mathrm{Cu}_{2-} \mathrm{NiSnS}_{4}$, неравновесные носители, времена жизни, кинетика.

DOI: 10.21883/FTP.2021.12.51702.9677

\section{1. Введение}

В настоящее время все большее развитие получают различные новые источники энергии, в том числе фотовольтаические преобразователи. Одним из перспективных материалов для их создания представляются четверные соединения меди со структурой кестерита $\mathrm{Cu}_{2-\delta} \mathrm{ZnSnS}_{4-y} \mathrm{Se}_{y}$ (CZTS(Se)). Однако к настоящему времени кпд солнечных элементов на их основе не превышает $13 \%$, что существенно ниже теоретического предела Шокли-Квиссера $(\sim 30 \%)$ [1]. По-видимому, это обусловлено структурой материала. Предполагается, что из-за близости ионных радиусов $\mathrm{Zn}^{2+}$ и $\mathrm{Cu}^{+}$в таком материале образуется большое количество антиструктурных дефектов $\mathrm{Cu}_{\mathrm{Zn}}$ и $\mathrm{Zn}_{\mathrm{Cu}}$, которые являются ловушками для носителей заряда [2,3]. Поэтому существенный научный и практический интерес представляет замена ионов в катионной подрешетке данного материала ионами с радиусом, отличным от такового для $\mathrm{Cu}^{+}$.

Такими материалами являются четверные соединения меди с общей формулой $\mathrm{Cu}_{2-} \mathrm{NiSnS}_{4}$ (CNTS) [4,5]. Одним из факторов, определяющих эффективность солнечного элемента, является время жизни фотогенерированных носителей заряда в полупроводнике.

Наиболее распространенным методом, позволяющим исследовать кинетику гибели фотогенерированных носителей заряда, является метод время-разрешенной люминесценции [6], основанный на исследовании кинетики затухания спектра излучения. Однако этим методом регистрируются только процессы, протекающие с излу- чением света, - например, рекомбинационная люминесценция. Для регистрации процессов гибели свободных носителей заряда, идущих без излучения света, захват акцепторами, ловушками, электронно-дырочная рекомбинация, рекомбинация через локализованные состояния, в том числе для случая безызлучательной люминесценции, - метод не пригоден. Электрические методы применимы в более общем случае.

Одним из таких методов является метод частотно-время-разрешенной микроволновой фотопроводимости $[7,8]$. В данной работе бесконтактным методом микроволновой фотопроводимости исследовано влияние содержания меди на кинетику гибели неравновесных носителей заряда в соединениях $\mathrm{Cu}_{2-\delta} \mathrm{NiSnS}_{4}$ $(0 \leq \delta \leq 0.2)$, полученных методом твердофазного ампульного синтеза.

\section{2. Экспериментальная часть}

Образцы для исследования получали методом прямого синтеза из элементных меди $(4 \mathrm{~N})$, никеля $(3 \mathrm{~N})$, олова (4N) и серы (ОСЧ). Синтез проводился в вакуумированных (остаточное давление $p=10^{-2}$ мм рт.ст.) карбонизированных кварцевых ампулах в несколько этапов. На первом этапе получали $\mathrm{NiS}$ и тройное соединение $\mathrm{Cu}_{2-\delta} \mathrm{SnS}_{3}$ из соответствующих элементов. Синтез проводился при $T=1100^{\circ} \mathrm{C}$ в течение 10 ч. После охлаждения содержимое ампул растиралось в агатовых ступках для гомогенизации вновь запаивалось под вакуумом и отжигалось при $T=740^{\circ} \mathrm{C}$ в течение 48 ч. 
На следующем этапе необходимые количества $\mathrm{NiS}$ и $\mathrm{Cu}_{2-\delta} \mathrm{SnS}_{3}$ помещались в вакуумированную кварцевую ампулу и отжигались при $T=1100^{\circ} \mathrm{C}$ в течение 10 ч. На заключительном этапе полученные слитки растирались в агатовых ступках, запаивались в ампулу под вакуумом и отжигались при $T=520^{\circ} \mathrm{C}$ в течение 600 ч.

Для определения структуры синтезированных образцов проводился рентгенофазовый анализ (РФА) на дифрактометре „PANalyticap Aeris diffractometer“ (излучение $\mathrm{Cu} K_{\alpha}$ ), АЦКП ИПХФ РАН. Определение фазового состава проводилось с использованием электронной базы кристаллографических данных ICDD XPDF-4+2020. При обработке дифрактограмм использовали комплекс программного обеспечения WinXPOW. Дополнительно фазовый состав исследовался методом рамановской спектроскопии („Bruker Senterra micro-Raman system“, излучение 532 нм).

Для исследования кинетики гибели фотогенерированных носителей заряда применен метод время-разрешенной микроволновой фотопроводимости в диапазоне частот 36 ГГц („Установка для измерения времен жизни фотогенерированных носителей тока методом микроволновой фотопроводимости в диапазоне частот 36 ГГц“") при комнатной температуре. Временно́е разрешение регистрирующей цепи было $\sim 5$ нс $[7,8]$. Фотопроводимость возбуждали азотным лазером ЛГИ-21 с длиной волны излучения $\lambda=337$ нм и длительностью импульса 8 нс. Максимальная плотность светового потока, падающего на образец за импульс (экспозиция), составляла $10^{15}$ фотон/см ${ }^{2}$. Интенсивность света в экспериментах изменяли с помощью светофильтров.

\section{3. Результаты и обсуждение}

На рис. 1 приведены рентгенограммы синтезированных образцов.

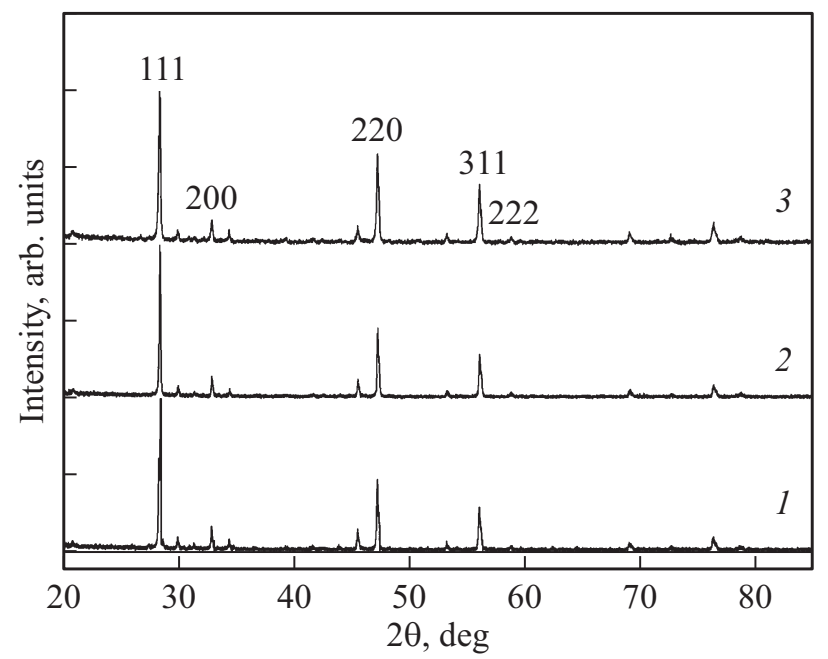

Рис. 1. Данные РФА для образцов $\mathrm{Cu}_{2-\delta} \mathrm{NiSnS}_{4}: \delta=0$ (1), $0.1(2), 0.2(3)$.

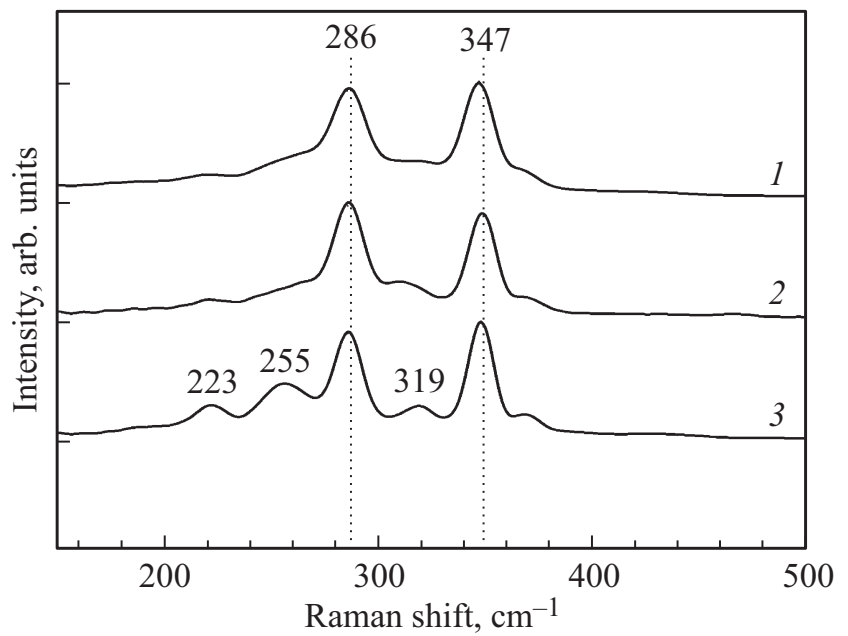

Рис. 2. Данные рамановской спектроскопии для образцов $\mathrm{Cu}_{2-\delta} \mathrm{NiSnS}_{4}: \delta=0$ (1), 0.1 (2), 0.2 (3).

Из рисунка видно, что все наиболее яркие линии соответствуют основной фазе $-\mathrm{Cu}_{2-\delta} \mathrm{NiSnS}_{4}$ (ICDD PDF-4+2020, card № 00-026-0552). Структура кубическая, пространственная группа $F-43 \mathrm{~m}$. Уточненные параметры кристаллической решетки таковы: $a=5.41 \AA, V=161.4 \AA^{3}$ для $\mathrm{Cu}_{2} \mathrm{NiSnS}_{4}, a=5.45 \AA$, $V=161.8 \AA^{3}$ для $\mathrm{Cu}_{1.9} \mathrm{NiSnS}_{4}, a=5.45 \AA, V=161.9 \AA^{3}$ для $\mathrm{Cu}_{1.8} \mathrm{NiSnS}_{4}$.

На рис. 2 приведены рамановские спектры синтезированных образцов.

Литературные данные о положении пиков в рамановских спектрах противоречивы [9-11]. Положения наиболее ярких пиков полученных нами рамановских спектров $\left(347\right.$ и $\left.286 \mathrm{~cm}^{-1}\right)$ оказались близкими к приведенным в работе [10]. Поэтому данные линии можно отнести к основной фазе - CNTS. Для образцов с $\delta=0.2$ наряду с линиями, характерными для CNTS, наблюдаются линии примесных фаз $\left(223,255,319 \mathrm{~cm}^{-1}\right)$. Такими фазами могут быть сульфиды меди $-\mathrm{Cu}_{2} \mathrm{SnS}_{3}$ или $\mathrm{Cu}_{2} \mathrm{NiSn}_{3} \mathrm{~S}_{8}$.

Исследование кинетики гибели фотогенерированных носителей заряда показало, что при включении света отраженная мощность сначала резко возрастала „фотоотклик“, а затем постепенно возвращалась к исходному состоянию. Анализ всех экспериментальных данных показал, что скорость спадов фотоотклика была достаточно большой, так что определение формы спадов было затруднительно. Для примера на рис. 3 приведены спады микроволновой фотопроводимости для порошков $\mathrm{Cu}_{2} \mathrm{NiSnS}_{4}$ и $\mathrm{Cu}_{1.9} \mathrm{NiSnS}_{4}$. Из рисунка видно, что амплитуда фотоотклика отличается приблизительно в 2 раза, а рассчитанные времена спадов составляют 7 нс (ограничиваются временны́ разрешением установки).

Зависимости $\Delta P_{\max }(I)$ практически для всех образцов были нелинейные (для примера см. рис. 4), а характеристическое время спада не зависело от интенсивности $I$ падающего света. Это может означать, что в эксперименте на временах $<5$ нс происходили процессы 


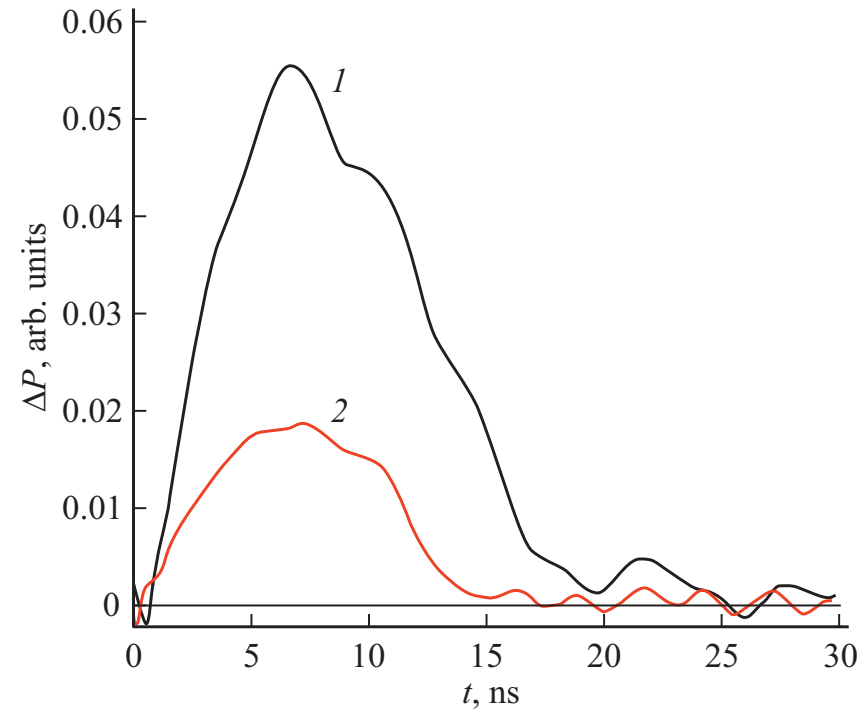

Рис. 3. Спады микроволновой фотопроводимости для порошков $\mathrm{Cu}_{2} \mathrm{NiSnS}_{4}(1)$ и $\mathrm{Cu}_{1.9} \mathrm{NiSnS}_{4}(2) . I=8.7 \cdot 10^{14}$ фотон $\cdot \mathrm{cm}^{-2}$ за импульс. Кривые сглажены с помощью линейного фильтра по 7 точкам.

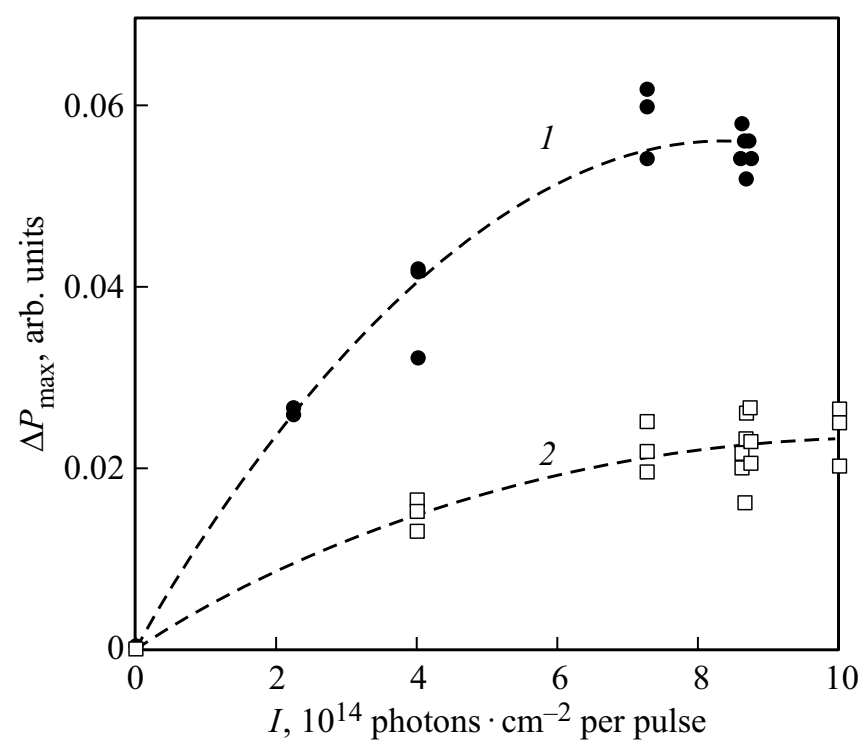

Рис. 4. Зависимости амплитуды фотоотклика от интенсивности падающего света для порошков $\mathrm{Cu}_{2} \mathrm{NiSnS}_{4}$ (1) и $\mathrm{Cu}_{1.9} \mathrm{NiSnS}_{4}$ (2).

2-го порядка реакции (рекомбинация свободных электронов и дырок):

$$
e^{-}+p^{+} \stackrel{k_{\mathrm{rec}}}{\longrightarrow} \ldots
$$

Однако на начальном участке $\Delta P_{\max }(I)$ наблюдается линейная зависимость вплоть до $I=3 \cdot 10^{14}$ фотон $\cdot \mathrm{cm}^{-2}$ за импульс, свидетельствуя, вероятно, о том, что для интенсивностей падающего света $<3 \cdot 10^{14}$ фотон $\cdot \mathrm{cm}^{-2}$ за импульс преобладающим становится процесс 1-го порядка - захват носителей заряда на ловушки:

$$
\begin{aligned}
& e^{-}+A \stackrel{1 / \tau_{\mathrm{tr}}^{e}}{\longrightarrow} A^{-}, \\
& p^{+}+B \stackrel{1 / \tau_{\mathrm{tr}}^{p}}{\longrightarrow} B^{+},
\end{aligned}
$$

где $\tau_{\mathrm{tr}}^{e}$ и $\tau_{\mathrm{tr}}^{p}-$ времена жизни до захвата в ловушки электронов и дырок соответственно. Тогда для $I=3 \cdot 10^{14}$ фотон $\cdot \mathrm{cm}^{-2}$ за импульс становится справедливым соотношение $\tau_{\mathrm{tr}}^{e}=\tau_{\mathrm{rec}}=1 / k_{\mathrm{rec}} k_{\mathrm{B}} \beta I$, где $k_{\mathrm{rec}}-$ константа скорости реакции электронно-дырочной рекомбинации, $k_{\mathrm{B}}-$ коэффициент поглощения, $\beta$ квантовый выход, и можно оценить времена жизни носителей заряда. Если предположить, что в соответствии с [10] для ширины запрещенной зоны 1.2 эВ [9] $k_{\text {rec }} \sim 10^{-10} \mathrm{~cm}^{3} \cdot \mathrm{c}^{-1}$, а $k_{\mathrm{B}}=10^{6} \mathrm{~cm}^{-1}$ [11], то $\tau_{\mathrm{tr}}^{e} \approx 0.03$ нс. Видно, что рассчитанное нами время до захвата носителей заряда приблизительно на 2 порядка отличается от измеренного нами характеристического времени спадов фотоотклика. Это, возможно, означает, что в эксперименте наблюдается не захват носителей заряда, а уже так называемые „вторичные“ процессы, обусловленные процессами (4)-(6):

$$
\begin{aligned}
& p^{+}+A^{-} \stackrel{1 / \tau_{\mathrm{rec}}}{\longrightarrow} A, \\
& A^{-} \stackrel{1 / \tau^{e}}{\longrightarrow} e^{-}+A, \\
& B^{+} \stackrel{1 / \tau^{p}}{\longrightarrow} p^{+}+B,
\end{aligned}
$$

где $\tau_{\text {rec }}-$ время жизни до рекомбинации локализованных электронов и свободных дырок (рекомбинация через локальные центры), $\tau^{e}$ и $\tau^{p}-$ времена термического выхода захваченных носителей заряда из электроных $(A)$ и дырочных $(B)$ ловушек соответственно.

Таким образом, оцененные времена до захвата фотогенерированных носителей заряда в $\mathrm{Cu}_{2-\delta} \mathrm{NiSnS}_{4}$ оказались меньше времен жизни для поликристаллических кестеритов CZTS, полученных нами ранее методом микроволновой фотопроводимости [11], а также полученных авторами [12] методом время-разрешенной люминесценции. Однако времена жизни повторно вышедших из ловушек носителей заряда составляют $\sim 7$ нс, и они сравнимы с литературными данными.

\section{4. Заключение}

Таким образом, методом твердофазного синтеза из элементных $\mathrm{Cu}, \mathrm{Ni}, \mathrm{Sn}$ и $\mathrm{S}$ синтезированы образцы $\mathrm{Cu}_{2-\delta} \mathrm{NiSnS}_{4}(0 \leq \delta \leq 0.2)$. Методами РФА и рамановской спектроскопии определена структура и уточнены параметры кристаллической решетки синтезированных образцов. Впервые бесконтактным методом время-разрешенной микроволновой фотопроводимости исследована кинетика гибели фотогенерированных носителей заряда в порошках $\mathrm{Cu}_{2-\delta} \mathrm{NiSnS}_{4}$. Показано, что при интенсивностях падающего света $>3 \cdot 10^{14}$ фотон $\cdot \mathrm{cm}^{-2}$ за импульс 
процессы электронно-дырочной рекомбинации преобладают над процессами захвата носителей заряда. При этом наблюдаемые измеренные времена жизни фотогенерированных носителей тока $(\tau \approx 7$ нс) значительно больше времен жизни до захвата $(\sim 0.03$ нс), оцененных из значения ширины запрещенной зоны CNTS, что, повидимому, обусловлено вторичными процессами.

Авторы выражают благодарность к.ф.-м.н. Г.В. Шилову и к.Х.н. Д.В. Корчагину за проведение ренгенофазового исследования.

Работа выполнена с использованием УНУ „Установка для измерения времен жизни фотогенерированных носителей тока методом микроволновой фотопроводимости в диапазоне частот 36 ГГц“ и АЦКП ИПХФ РАН в рамках государственного задания № AAAA-A19-119070790003-7.

\section{Конфликт интересов}

Авторы заявляют, что у них нет конфликта интересов.

\section{Список литературы}

[1] W. Shockley, H.J. Queisser. J. Appl. Phys., 32 (3), 510 (1961).

[2] M.S. Kumar, S.P. Madhusudanan, S.K. Batabyal. Sol. Energy Mater. \& Sol. Cells, 185, 287 (2018).

[3] K. Ito. Copper Zinc Tin Sulfide-Based Thin-Film Solar Cells (West Sussex, U.K., John Wiley and Sons, Ltd, 2015).

[4] S. Rondiya, N. Wadnerkar, Y. Jadhav, S. Jadkar, S. Haram, M. Kabir. Chem. Mater., 29, 3133 (2017).

[5] A. Ghosh, R. Thangavel, M. Rajagopalan. Energy and Environment Focus, 3, 142 (2014).

[6] T. Sakurai, K. Taguchi, M.M. Islam, S. Ishizuka, A. Yamada, K. Matsubara, S. Niki, K. Akimoto. Jpn. J. Appl. Phys., 50, 05FC01 (2011).

[7] G.F. Novikov. J. Renewable \& Sustainable Energy, 7(1), 011204 (2015).

[8] М.В. Гапанович, Д.Н. Варсеев, Е.В. Рабенок, Б.И. Голованов, Г.Ф. Новиков. Химия высоких энергий, 53 (6), 432 (2019) [High Energy Chemistry, 53 (6), 429 (2019).]

[9] Hui-Ju Chen, Sheng-Wen Fu, Tsung-Chieh Tsai, ChuanFeng Shih. Mater. Lett., 166, 215 (2016).

[10] Г.Ф. Новиков, Н.А. Радычев. Изв. АН. Сер. хим., № 5, 856 (2007) [Russ. Chem. Bull., N 5, 890 (2007)].

[11] Г.Ф. Новиков, М.В. Гапанович, В.Ф. Гременок, К.В. Бочаров, W.-T. Tsai, Ming-Jer Jeng, Liann-Be Chang. ФТП, 51 (1), 22 (2017) [Semiconductors, 51 (1), 22 (2017)].

[12] I. Repins, C. Beall, N. Vora, C. DeHart, D. Kuciauskas, P. Dippo, B. To, J. Mann, Wan-Ching Hsu, A. Goodrich, R. Noufi. Sol. Energy Mater. \& Sol. Cells, 101, 154 (2012).

Редактор Л.В. Шаронова

\section{Stydy of loss kinetics of excess current carriers in the quarter copper compounds $\mathrm{Cu}_{2-\delta} \mathrm{NiSnS}_{4}(\mathbf{0} \leq \boldsymbol{\delta} \leq \mathbf{0 . 2})$}

M.V. Gapanovich ${ }^{1}$, E.V. Rabenok ${ }^{1}$, B.I. Golovanov ${ }^{1}$,
D.M. Sedlovets ${ }^{3}$, G.F. Novikov ${ }^{1,2}$

${ }^{1}$ Institute of Problems of Chemical Physics, Russian Academy of Sciences, 142432 Moscow region, Chernogolovka, Russia ${ }^{2}$ Faculty of Fundamental Physical and Chemical Engineering, Lomonosov Moscow State University, 119992 Moscow, Russia

${ }^{3}$ Institute of Microelectronics Technology and High Purity Materials, Russian Academy of Sciences, 142432 Chernogolovka, Russia

Abstract The method of solid-phase synthesis from element $\mathrm{Cu}, \mathrm{Ni}, \mathrm{Sn}$ and $\mathrm{S}$ the samples $\mathrm{Cu}_{2-\delta} \mathrm{NiSnS}_{4}(0 \leq \delta \leq 0.2)$ were obtained. The parameters of their crystal lattice are refined. For the first time the contactless method of time resolved microwave photoconductivity was used to estimate life times of photogenerated current carriers in $\mathrm{Cu}_{2-\delta} \mathrm{NiSnS}_{4}$. These times have turned out $\tau \approx 7 \mathrm{~ns}$ that is comparable to literary data for CZTS kesterites. At the same time in loss kinetics of the photogenerated current carriers the prevalence of processes of bimolecular recombination over capture processes is observed. 